Research Article

\title{
Can a Manufacturer Get Better off When Providing Product Sharing Services?
}

\author{
Xiaozheng Li, ${ }^{1}$ Xiaojian $\mathrm{Hu} \mathbb{D}^{1},{ }^{1,2} \mathrm{Ju}$ Qiu, ${ }^{1}$ and Xinxuan $\mathrm{Zhu}^{3}$ \\ ${ }^{1}$ School of Management, Hefei University of Technology, Hefei 230009, China \\ ${ }^{2}$ Key Laboratory of Process Optimization and Intelligent Decision-making, Ministry of Education, Hefei 230009, China \\ ${ }^{3}$ Intelligent Manufacturing Institute of Hefei University of Technology, Hefei 230009, Anhui, China
}

Correspondence should be addressed to Xiaojian Hu; xiaojianhu@sohu.com

Received 18 November 2020; Revised 25 January 2021; Accepted 3 February 2021; Published 23 February 2021

Academic Editor: Polinpapili ho F. Katina

Copyright ( 92021 Xiaozheng Li et al. This is an open access article distributed under the Creative Commons Attribution License, which permits unrestricted use, distribution, and reproduction in any medium, provided the original work is properly cited.

The emerging product sharing trend poses challenges for manufacturers. Although the cost of purchasing products is decreased by adopting product sharing, consumers must accept that their demand cannot be responded to instantly and must use unfamiliar shared products. There are unavoidable inconveniences that are inherent in product sharing that directly affect consumers' choices and further affect manufacturers' decisions about providing sharing services. However, few papers have focused on the impact of such factors. In this paper, we aim to study how the unavoidable inconvenience costs and operational costs affect the manufacturer's decision on whether to provide sharing services. First, low inconvenience cost and operational cost encourage the manufacturer to provide sharing services. High product quality weakens the influence of these two factors, while strengthening the influence of the pooling effect on the manufacturer's provision decision. Second, the sharing market cannibalizes the sales demand when inconvenience cost is low and product quality is high. Third, the provision of sharing services is a win-win situation for consumers and the manufacturers of low-quality products.

\section{Introduction}

Currently, product sharing has expanded widely around the world. The transaction mode, which focuses on providing the right to use, rather than transferring ownership, has become an important business trend. China's State Information Centre has stated that the transaction volume of the sharing economy market in 2019 was 3282.8 billion yuan, an increase of $11.6 \%$ over the previous year (http://www.sic. gov.cn/News/568/10429.htm). This emerging trend has changed ways of living. A growing number of people choose to use shared products rather than buy them. In addition, many firms have undertaken action to embrace the new challenges and gain advantages in the changing business world. For example, Daimler has included the car sharing program Car2Go in its sales business. Ann Taylor, the American fashion retailer, recently launched the sharing service Infinite Style (https://www.anntaylor.com/how-itworks/cat3880004). Other fashion groups, such as LVMH, are now considering joining the sharing market by merging with Rent the Runway, founded in 2009, with the simple philosophy of renting designer clothing and accessories to women rather than selling them (https://www. renttherunway.com/plans? \&source=unlimited_lp-

unlimited_lp_hero). Even though the phenomenon that the firms include product sharing services is conspicuous, the understanding of this is limited. In this paper, our aim was to study the impact of product sharing on traditional sales and to guide manufacturers in making the choice of whether or not to introduce sharing services to complement their sales.

The extant literature has studied how the marginal production cost and transaction cost of sharing $[1,2]$, capacity constraints $[3,4]$, and vertical differentiation [5] affect traditional firms in introducing product sharing. However, we have found that the inconvenience cost borne by the renter also plays a critical role. For example, in the apparel industry, people can rent clothes and luxury goods for grand occasions from Rent the Runway instead of buying, but their 
needs cannot be meet instantly. They must send the clothes back by express shipping or go to stores to pick up and return them every time that they rent them. In the sharing transportation area, different from owning a car, which can be used instantly, car renters bear the inconvenience of picking up and returning the cars at designated stations. In addition, they also must bear the inconvenience of familiarizing themselves with the vehicle model quickly to ensure safe driving. Such inconvenience is difficult to eliminate. It directly affects consumers' buying and renting decisions, and further affects the sharing demand and firms' decisions about entering the sharing market.

When manufacturers provide product sharing services, it is in the form of business-to-consumer (B2C) product sharing. They must bear operational costs to reduce the inconvenience of sharing. They are responsible for the scheduling, technical support, and routine maintenance of the shared products. Under B2C product sharing, consumers can retrieve and return the products at shared product storage/parking sites. Manufacturers must tradeoff between the increases in sharing demand brought about by the convenient sharing experience and the increases in operational cost to reduce consumers' inconvenience. Therefore, we also analyze the influence of the operation cost for manufacturers to provide sharing services.

Moreover, although providing product sharing services to complement sales business brings profits to manufacturers, it also cannibalizes the sales market because some people who had planned to buy will now choose to rent. Some researchers have examined how the strength of the pooling effect impacts cannibalization $[5,6]$. They have demonstrated that, as the strength increases, the sharing market cannibalizes more sales demand. We also analyze the influence of the pooling effect on the cannibalization between the sharing and selling markets. Furthermore, we analyze the influence of product quality on cannibalization. Different product levels lead to different degrees of cannibalization and further affect manufacturers' decisionmaking [7], which can be verified in reality. For example, many high-end automobile producers have already entered the sharing market by providing car sharing schemes (i.e., BMW, GE). Therefore, achieving a deeper understanding of the impact of these two factors is essential.

Based on the above considerations, we are motivated to analyze the following research questions. Should a traditional manufacturer who originally sells products provide product sharing services simultaneously? How does the strategic decision regarding whether to provide product sharing services influence the traditional sales market? And, how are consumer surplus and social welfare affected by the provision of product sharing services? To formally analyze the role of product sharing in the manufacturer's sharing decision, we develop pricing game models under two scenarios. One is that the manufacturer acts only as the seller and directly sells products to consumers. The other is that the manufacturer acts as both the seller and the sharing service provider. Within this setup, we investigate the influence of product sharing on the traditional sales market and the manufacturer's profits.
Our main results are as follows. First, low inconvenience cost and operational cost motivate the manufacturer to provide product sharing services. As the product quality increases, the manufacturer becomes more willing to provide product sharing services. This finding suggests that manufacturers that produce high-quality products can benefit from entering the sharing market. For those who produce low-quality products, maintaining the original sales business is a better choice. Second, providing product sharing services brings cannibalization effects. Low inconvenience cost and high product quality allow the product sharing to erode the sales demand and increase the selling price. Thus, the manufacturer should undertake actions to improve the convenience of the sharing experience and launch low-quality products for sharing to alleviate the negative effects of cannibalization. Third, adding product sharing services to sales businesses is a win-win business mode that benefits both the manufacturer, which provides sharing services for low-quality products, and the consumers.

The remainder of this paper is as follows. Section 2 reviews the literature relevant to our study. Section 3 describes our model, and Section 4 provides a detailed analysis and mathematical studies. Section 5 discusses the results and their implications from the academic and industry perspectives. Section 6 concludes the paper and provides future research directions.

\section{Related Literature}

The existing literature has examined the influence of product sharing on society $[8,9]$ and traditional industry $[1,3,10-12]$. Sun et al. [8] and Ding and Shuai [9] investigate the impact of product sharing on market regulation and alleviating traffic congestion. Other researches find that how much the firm can benefit from the sharing services depends on the production cost $[1,11]$, the capacity cost [3], the cost of ownership [10], and the shared product value [12] However, this part of the research takes product sharing as the external market environment, and enterprises do not provide product sharing services. What is more relevant to our research is the strategy of manufacturers to enter the sharing market. Some researchers have discussed the manufacturer's entry strategy from the perspectives of consumer heterogeneity [13], the consumer's perceived value [14], product availability [15], uncertain information [16], the population's peer-trade propensity [17], and operational factors related to after-sales services [18], which affect the manufacturer's decision to join the sharing market. Some researchers have emphasized the impact of product quality on the manufacturer's strategy of entering the sharing market. Yu et al. [5] demonstrated that a certain degree of vertical differentiation motivates the manufacturer to enter the sharing market. Bellos et al. [19] found that low product quality attracts the manufacturer to provide a product sharing scheme. Some research has investigated the effect of the production costs, operational cost, and inconvenience cost of product sharing on the manufacturer's entry strategy. Jiang et al. [20] and Pei et al. [21] both found 
that the manufacturer provides product sharing services when the production cost is high. Dai and $\mathrm{Nu}$ [4] showed that, when production cost is low, the manufacturer prefers to provide $\mathrm{B} 2 \mathrm{C}$ product sharing; otherwise, the manufacturer prefers to provide $\mathrm{C} 2 \mathrm{C}$ product sharing. Their research showed that operational costs, inconvenient costs, and product quality have important impacts on the manufacturer's strategy of entering the sharing market. However, to the best of our knowledge, few researchers have considered these factors together and comprehensively analyzed their influence on manufacturers' product sharing decisions. In our research, we complement the deficiency of this part of the research and comprehensively consider the influences of product quality, inconvenience cost, operation cost, and pooling effect. We find that they all affect the manufacturer's strategy of entering the sharing market.

Our work is also related to the pay-per-use (PPU) pricing mechanism, which was first applied in the information goods and streaming media industry. Balasubramanian et al. [22], Cachon and Feldman [23], Sato and Nakashima [24], and Li et al. [25] studied the factors that influence the decision to choose the PPU pricing strategy from the perspective of psychological cost, service congestion, uncertainty of consumers' usage frequency, and the advertising revenue rate and consumers' retention value. However, their study focused on the area of information goods and omitted the production cost. There are some other researchers that compare the selling and PPU pricing mechanisms of durable goods. Toffel [26] compares the hazards between sales and PPU transactions. Ladas et al. [27], Gilbert et al. [28], and Agrawal et al. [29] analyze the profitability of PPU pricing strategy from the perspective of logistics cost, consumer usage, and product durability. Although in our research we adopt the PPU pricing mechanism in $\mathrm{B} 2 \mathrm{C}$ product sharing services and also consider the heterogeneous consumer usage, our research focuses on the manufacturer's business mode choice of considering to include product sharing services, rather than comparing the pricing strategy of sales and PPU.

\section{The Model}

We consider a manufacturer who produces one type of product with quality $q$ at marginal cost $c$. To investigate the conditions under which the manufacturer should provide product sharing services, we develop two models: pure sales and sharing services. Figure 1(a) depicts a manufacturer that does not join the sharing market, acts only as the seller, and directly sells products to consumers. Figure 1(b) depicts a manufacturer that joins the sharing market and provides product sharing services to consumers, as well as selling products. In this section, we analyze the consumers' choices and the manufacturer's decisions on prices under these two scenarios individually. We use the superscripts $S$ and $R$ to denote the scenarios of pure sales and including sharing services, respectively.

To explain the consumer's choice, we introduce the concept of the usage level $[5,6]$, which represents the amount of use that a consumer has for a product. For example, how long or how often a consumer needs to use a car or how much time on a shared power bank the renter will spend to charge his/her phone. We assume that the usage level for each individual is heterogeneous and uniformly distributed from 0 to 1 , i.e., $\mu \sim U[0,1]([][5,6])$. In particular, $\mu=0$ corresponds to the consumer does not use the product at all, while $\mu=1$ corresponds to the consumer fully uses the product. Without loss of generality, we assume the market size in our model is one $[5,6]$.

3.1. Benchmark: Pure Sales. Before the manufacturer participates in the sharing market, the manufacturer only sells products to consumers. The owner must pay the selling price $\left(p_{s}^{S}\right)$ and can obtain the salvage value $\left(\varepsilon_{s}\right)$ of the product. Therefore, a consumer's utility in buying a product with quality $q$ is

$$
U_{s}^{S}=\mu q-p_{s}^{S}+\varepsilon_{s}
$$

Thus, if the consumer uses the product more, i.e., $\mu \in\left[\mu^{S}, 1\right]$, where $\mu^{S}=\left(p_{s}^{S}-\varepsilon_{s} / q\right)$, he/she will choose to buy it and become the owner. Otherwise, he/she will leave the market and seek outside options. Therefore, the sales demand is $D_{s}^{S}=1-\mu^{S}$.

The manufacturer determines the selling price $p_{s}^{S}$ to maximize profit. To exclude trivial or unrealistic cases, we make some technical assumptions. First, we assume that the salvage value of the purchased product and the marginal production cost depend on the product quality $q$, denoted as $\varepsilon_{s}=(1 / 2) k_{2} q^{2}$ and $c=(1 / 2) k_{1} q^{2}$, respectively. The coefficients $k 2$ and $k 1$ are exogenous. Second, to ensure that the demand in the sales market is positive and that the whole market is not fully covered, we assume that $0<p_{s}^{S}-\varepsilon_{s}<q$. Third, we also assume that $p_{s}^{S}>c$ to ensure positive profits. Therefore, we obtain the manufacturer's profit as follows:

$$
\Pi_{s}^{S}=\left(p_{s}^{S}-c\right) D_{s}^{S} \text {. }
$$

Theorem 1. Before including the product sharing services, the optimal price, demand, and profit of the manufacturer are $p_{s}^{S *}=\left(q\left(k_{1} q+k_{2} q+2\right) / 4\right), D_{s}^{S *}=\left(2-q\left(k_{1}-k_{2}\right) / 4\right)$, and $\Pi_{s}^{S *}=\left(q\left(k_{2} q-k_{1} q+2\right)^{2} / 16\right)$, respectively.

Theorem 1 implies that the optimal demand in the sales market is always less than $1 / 2$, i.e., holding less than half of the total market. It is easy to observe that high product quality leads to an improved selling price, a decline in the sales market demand, and an increase in profit. In addition, a high consumer salvage value coefficient leads to an increase in the selling price, demand, and profit.

3.2. Providing Product Sharing Services. After the manufacturer joins the sharing market, consumers have two choices: buying or renting. A consumer makes this choice according to the utility derived from each alternative. As an owner, the consumer must pay the selling price $\left(p_{s}^{R}\right)$ at one time and can obtain the salvage value $\left(\varepsilon_{s}\right)$ of the product. Therefore, a consumer's utility in buying a product with quality $q$ is obtained as 


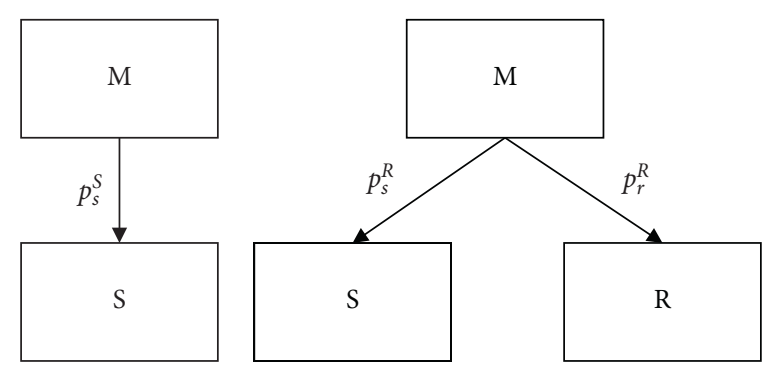

(a)

(b)

Figure 1: The channel structures of the two models. (a) Pure sales. (b) Providing product sharing services.

$$
U_{s}^{R}=\mu q-p_{s}^{R}+\varepsilon_{s} .
$$

As a renter, the consumer must pay for every unit that he/she uses, and he/she bears the inconvenience cost that accompanies the per-unit usage $(d)$, which results from the inconvenience of using the product without ownership and from the billing method of PPU product sharing. Therefore, a consumer's utility in renting a product at the usage level $\mu$ is described as

$$
U_{r}^{R}=\mu\left(q-p_{r}^{R}-d\right)
$$

where $p_{r}^{R}$ is the sharing price.

When $U_{s}^{R} \geq \max \left\{U_{r}^{R}, 0\right\}$, the consumer will choose to buy the product, i.e., $\mu \in\left[\mu^{R}, 1\right]$; when $\mu^{R}=\left(p_{s}^{R}-\varepsilon_{s} / p_{r}^{R}+d\right)$, hel she will choose to buy it and become the owner. Otherwise, if $U_{r}^{R} \geq \max \left\{U_{s}^{R}, 0\right\}$, he/she will choose to rent the product. Therefore, the sales market demand is $D_{s}^{R}=1-\mu^{R}$. When $\mu \in\left[0, \mu^{R}\right)$, the consumer chooses to rent, and the sharing market size is $D_{r}^{R}=\mu^{R}$.

The manufacturer determines both the selling price $\left(p_{s}^{R}\right)$ and the sharing price $\left(p_{r}^{R}\right)$, and obtains the salvage value due to holding the ownership of the shared products. Under the sharing option, the renters will not value using the shared products as highly as using their purchased goods, and shared products are used more often than the purchased ones. Thus, we assume that the salvage value obtained by the manufacturer is less than that of the owner: $0<k_{3}<k_{2}<k_{1}<1$. In product sharing, one product can satisfy various consumers' needs in different time periods; i.e., there is a pooling effect. As a result, the total number of products launched in the sharing market is no greater than $D_{r}^{R}$. The manufacturer enjoys the cost advantage gained by the pooling effect. We use the coefficient $\gamma \in[0,1]$ to denote the strength of the pooling effect [5]. The actual number of products launched in the sharing market is $\gamma D_{r}^{R}$. The lower the value of the pooling effect coefficient is, the greater is the cost advantage enjoyed by the manufacturer. The strength of the pooling effect depends on the synchronicity of sharing demand generation; in other words, the degree of overlap of the time periods in which renters generate demand. For example, if all consumers generate a sharing demand at the same time $(\gamma=1)$, the manufacturer must designate a particular product to each renter, and the actual demand in the sharing market equals the sharing market size, i.e., $\gamma D_{r}^{R}=D_{r}^{R}$. The same is true in the sales market. In addition, the strength of the pooling effect also depends on the product category. For example, compared with a shared power bank, the pooling effect of a shared umbrella is lower. The demand for shared umbrellas is concentrated on rainy days, while the demand for power banks does not have such a pattern, and its demand is generated more randomly. In a sharing market, the total usage generated is $\Omega_{r}^{R}=\int_{0}^{\mu^{2}} \mu \mathrm{d} \mu$. The manufacturer must bear the unit operational cost $(f)$ when providing the product sharing service.

To exclude trivial or unrealistic cases, we make some technical assumptions. First, we assume that the salvage value of the shared product depends on the product quality $q$ and is denoted as $\varepsilon_{r}=(1 / 2) k_{3} q^{2}$. The coefficient $k_{3}$ is exogenous and $0<k_{3}<k_{2}<k_{1}<1$. Second, to ensure that the demand in both selling and sharing market is positive, we assume that $0<p_{s}^{R}-\varepsilon_{s}<q$ and $0<p_{s}^{R}-\varepsilon_{s}<q$, respectively. In addition, we also assume that $0<\left(p_{s}^{R}-\varepsilon_{s} / p_{r}^{R}+d\right)<1$ to ensure that the choices of buying and renting are both feasible for the consumer, and the demand from buying and that from renting both exist. Third, we assume that $p_{r}^{R}-$ $f>0$ and $\left[\left(p_{r}^{R}-f\right)\left(p_{s}^{R}-\varepsilon_{s}\right)\right] / 2\left(p_{r}^{R}-d\right)-\gamma\left(c-\varepsilon_{r}\right)>0$ to ensure that the manufacturer's profit after including the product sharing services is positive. The profit function of the manufacturer after sharing services are included is

$$
\Pi_{s r}^{R}=\Pi_{s}^{R}+\Pi_{r}^{R}=\left(p_{s}^{R}-c\right) D_{s}^{R}+\left(p_{r}^{R}-f\right) \Omega_{r}^{R}-\left(c-\varepsilon_{r}\right) \gamma D_{r}^{R} .
$$

Theorem 2. After including the product sharing services, the optimal price, demand, aggregate usage, and profits of the manufacturer are 


$$
\begin{aligned}
& p_{s}^{R *}=\frac{q^{2}\left[k_{2}(d+f)+q\left(k_{1}-k_{2}-k_{1} \gamma+k_{3} \gamma\right)+2\right]}{2(d+f+q)}, \\
& p_{r}^{R *}=q-d, \\
& D_{r}^{R *}=\frac{q\left[q\left(k_{1}-k_{2}-k_{1} \gamma+k_{3} \gamma\right)+2\right]}{2(d+f+q)}, \\
& D_{s}^{R *}=1-\frac{q\left[q\left(k_{1}-k_{2}-k_{1} \gamma+k_{3} \gamma\right)+2\right]}{2(d+f+q)}, \\
& \Omega_{r}^{R *}=\frac{q^{2}\left[q\left(k_{1}-k_{2}-k_{1} \gamma+k_{3} \gamma\right)+2\right]^{2}}{8(d+f+q)^{2}}, \\
& \Pi_{s r}^{R *}=\frac{q^{2}\left[q\left(k_{1}-k_{2}-k_{1} \gamma+k_{3} \gamma\right)+2\right]^{2}}{8(d+f+q)}-\frac{\left(k_{1}-k_{2}\right) q^{2}}{2} .
\end{aligned}
$$

Theorem 2 provides the optimal results after the manufacturer provides sharing services. It is obvious that, as the renter's inconvenience cost increases, the selling price decreases, and the demand increases; the sharing price, sharing demand, aggregate usage, and the total profit of the manufacturer all decrease. As the manufacturer's operational cost of sharing increases, the selling price decreases, and the demand increases; the sharing demand, aggregate usage, and the total profit of the manufacturer all decrease. As the product quality increases, the selling price and the sharing price both increase; the demand in the sales market decreases, while that in the sharing market increases; and the aggregate usage and the total profit of the manufacturer increase.

\section{Analysis}

In this section, we first analyze the impact of providing product sharing services on the traditional sales market. Next, we analyze the manufacturer's strategic decision regarding whether or not to include product sharing to complement its sales. Finally, we analyze the influence of product sharing on consumers and society by comparing consumer surplus and social welfare with and without product sharing.

\subsection{Impact of Providing Product Sharing on the Sales Market.} This subsection discusses the influence of adding product sharing services on the sales market. In particular, we explain how providing a product affects the demand and pricing strategy in the sales market and how it cannibalizes the sales profit. Our analysis develops from two perspectives: the renter's inconvenience cost and the product quality.

Proposition 1. If using the shared product is convenient, i.e., $0<d<q-f-\left(2 q^{2} \gamma\left(k_{1}-k_{3}\right) / q\left(k_{1}-k_{2}\right)+2\right)$, including the product sharing services increases the optimal selling price but decreases the demand in the sales market, i.e., $p_{s}^{R *}>p_{s}^{S *}$ and
$D_{s}^{R *}<D_{s}^{S *}$. Otherwise, if using the shared product is inconvenient, i.e., $\quad q-f-\left(2 q^{2} \gamma\left(k_{1}-k_{3}\right) / q\left(k_{1}-k_{2}\right)+2\right)$ $<d<1$, including the product sharing services lowers the optimal selling price but increases the demand in the sales market, i.e., $p_{s}^{R *}<p_{s}^{S *}$ and $D_{s}^{R *}>D_{s}^{S *}$.

Including the product sharing services results in a decrease in the profit derived from the sales market, i.e., $\Pi_{s}^{R *}<\Pi_{s}^{S *}$.

The first part of Proposition 1 analyzes the influence of adding product sharing services on the sales market. First, providing product sharing services cannibalizes the sales demand when the renter's inconvenience cost is low. When the renter can conveniently use shared products, providing product sharing will cannibalize the sales market. In contrast, inconvenience in using the shared product will expand the sales market because, when the two options of buying and renting are available and renting is very convenient, some consumers who planned to purchase might tend to rent the shared product. Second, adding product sharing services affects the pricing strategy in the sales market. When sales and sharing coexist, if the inconvenience of sharing is low, then the sales demand will fall, and the selling price will rise. Otherwise, the sales demand will rise, and the selling price will fall. Based on a previous discussion, when sales and sharing markets coexist, the more convenient it is to use the shared products, the more appealing the sharing option is for consumers. Therefore, the sales demand will decrease. The manufacturer will shrink the product supply, leading to an increase in the selling price. In contrast, when renting is very inconvenient, some people who planned to rent might tend to purchase the goods.

The second part of Proposition 1 shows that introducing product sharing will always cannibalize the profit from the sales market. In other words, the profit gained from the sharing market comes at the expense of profit or loss in the sales market. On the one hand, when the sales demand is cannibalized (or renting is quite convenient), some consumers still choose to buy. Although by increasing the selling price, the manufacturer can make up for the loss of the cannibalized demand, the total profit in the sales market goes down. On the other hand, when the sales demand is expanded (or renting is quite inconvenient), consumers are hesitant to choose shared products. In this case, to promote consumer purchases, the manufacturer lowers the selling price. Although sales are ultimately achieved, sales profits decline. However, if the manufacturer does not reduce prices, the loss of sales profits will be greater in magnitude. This outcome suggests that, when deciding whether or not to become a seller as well as a sharing service provider, the manufacturer should balance the gains and losses.

Next, we analyze how the product quality affects the optimal selling price and the sales market demand after the manufacturer provides product sharing. Due to the complexity of the problem, we illustrate this condition with numerical examples. We set the database as $k_{1}=1, k_{2}=0.6$, $k_{3}=0.4, \gamma=0.5, d=0.08$, and $f=0.1$. Because the changing trend is the same, to render the graph clearer, the value of $q$ only takes values from 0 to 0.3 in Figure 2(a). 


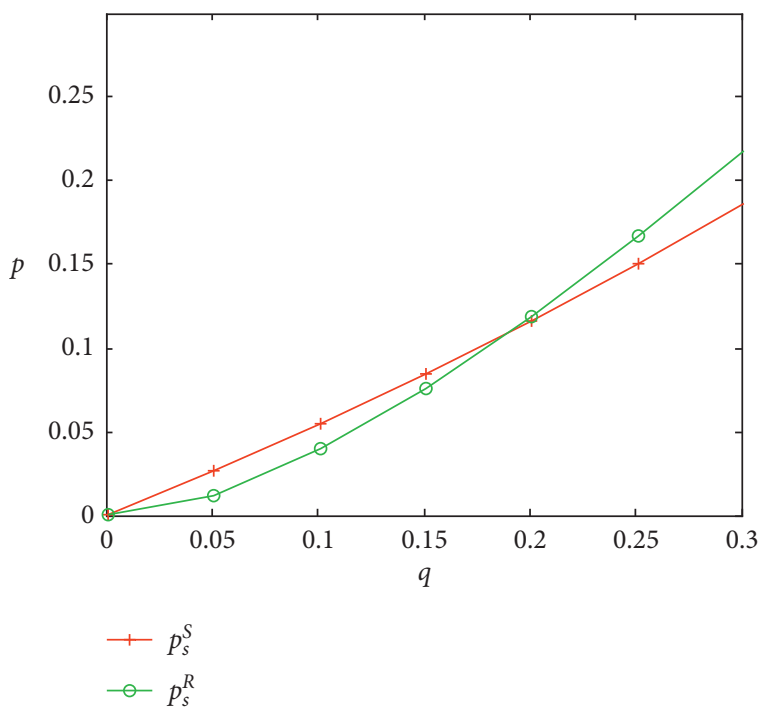

(a)

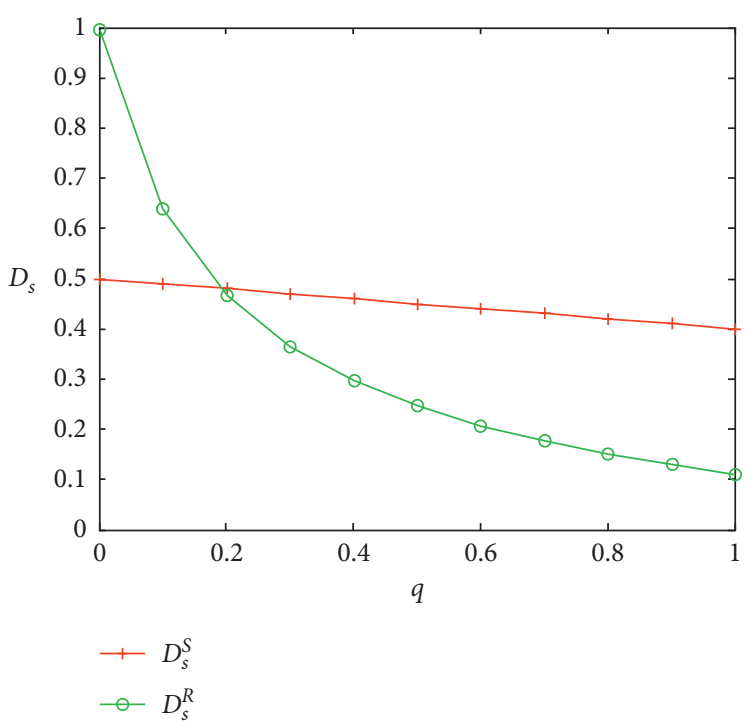

(b)

FIgUre 2: The effect of $q$ on price and demand in the sales market. (a) The effect of ( $q$ ) on selling prices. (b) The effect of ( $q$ ) on sales demand.

Figure 2 illustrates the impact of adding product sharing services on the sales market. After the manufacturer launches high-quality products on the sharing market, the sales demand is cannibalized. To be specific, when the product quality is low, providing product sharing expands the demand of the sales market. High product quality will cannibalize sales demand, implying that, as the product quality increases, the sharing market is more attractive to the manufacturer because low-quality products are affordable for consumers. The lower the selling price is, the more the consumers who choose to buy. Therefore, even if the manufacturer adds product sharing services, the sales demand will expand. Corresponding to the high product quality, the selling price is also high, prohibiting many people from buying and encouraging them to rent from the sharing market. Hence, adding product sharing services will cannibalize sales demand.

In addition, after the manufacturer joins the sharing market, if the product quality is low, the selling price decreases, and the demand increases. If the product quality is high, engaging the sharing market leads to a high selling price and low sales demand. By identifying its product quality, the manufacturer will know how product sharing will affect its pricing strategy in the traditional sales market. If the manufacturer's product quality is low, it is better to set a low selling price to access more consumers. If the manufacturer's product quality is high, it is better to set a higher selling price to gain a greater profit margin.

\subsection{Manufacturer's Strategic Decision on Providing Product} Sharing Services. In this subsection, we answer the question of the manufacturer's decision regarding whether or not to provide product sharing to complement its sales business. First, we investigate how the renter's inconvenience cost and owner's salvage value coefficient affect the manufacturer's decision when contemplating whether to join the sharing market. Second, we examine the effect of the operational cost of sharing and the strength of the pooling effect on the manufacturer's decision. The results are presented below.

In Figure 3, we see that, for any given buyer's salvage value coefficient $\left(k_{2}\right)$, decreasing the level of the renter's inconvenience cost $(d)$ encourages the manufacturer to include product sharing services to complement its sales. When the inconvenience cost is relatively low, joining the sharing market to provide sharing services is better for the manufacturer. When the inconvenience cost is between low and medium, as the salvage value coefficient decreases, the manufacturer's optimal decision evolves from not including to including the product sharing services. When the inconvenience cost is between medium and high, it is better for the manufacturer to adhere to its traditional sales and not provide sharing services.

Note that Proposition 1 states that the sales profit will definitely decrease if the manufacturer launches product sharing services. According to Theorem 2, a decrease in the inconvenience cost will lead to an increase in the aggregate usage and price in the sharing market, thus leading to high sharing revenue. Therefore, the intuition underlying the above results is that a low inconvenience cost gives the manufacturer greater advantages in terms of earning more revenue to compensate for the loss in the sales market after joining the sharing market and including the product sharing services.

These results provide executable managerial insights into the manufacturer's decision to provide sharing services as a complement to its sales. If the manufacturer is able to drastically reduce inconvenience costs, then joining the sharing market is more profitable. For instance, in the field of transportation, a car sharing manufacturer can reasonably plan the parking locations of shared cars to shorten the walking distance between the renter's parking spot and his/ 


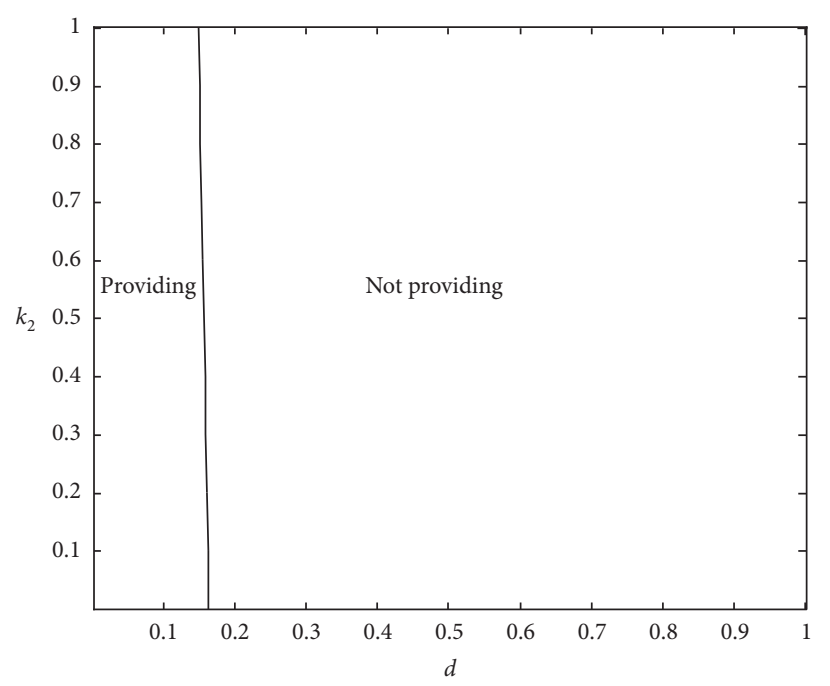

(a)

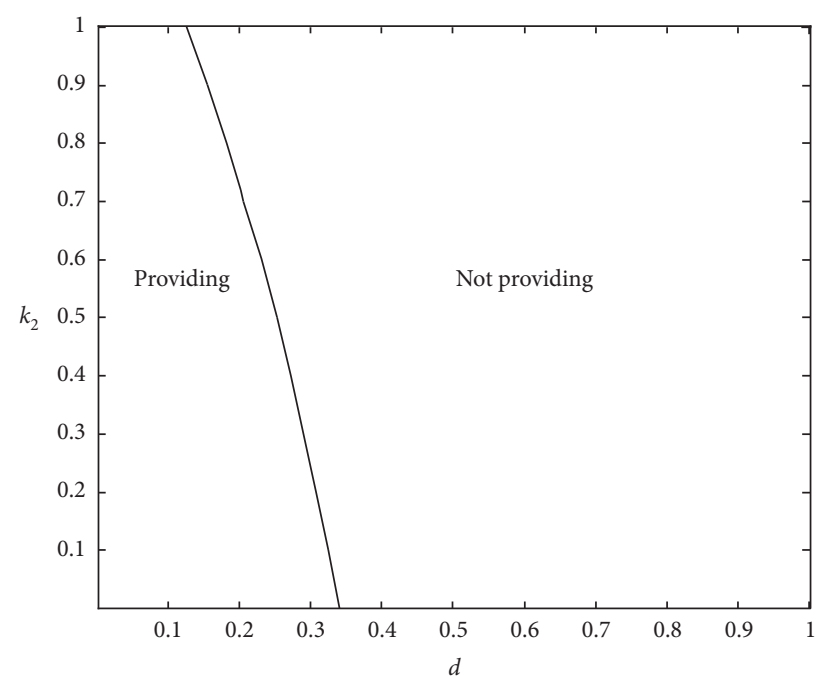

(b)

FIgURE 3: The effect of $d$ and $k 2$ on manufacturer's decision. (a) $q=0.35$. (b) $q=0.95$.

her final destination. Manufacturers can design product functions to facilitate sharing. For example, they can design cars that do not require a key to unlock. Simplifying the borrowing and returning process can also reduce inconvenience. Many bike sharing firms have already waived renters' deposits by accessing their credit records.

Second, comparing Figures 3(a) and 3(b), we observe that high product quality renders the manufacturer more willing to provide product sharing services. The increase in the product quality $(q)$ weakens the influence of the inconvenience cost and salvage value coefficient on the manufacturer's choice. When $q$ is low, for any given value of the buyer's salvage value coefficient, a slight decrease in the inconvenience cost will cause a change in the manufacturer's decision from not sharing to sharing. When the inconvenience cost falls from low to medium, similarly, a slight reduction in the salvage value coefficient will also cause this change. However, when the product quality is high, the magnitude of such a drop or reduction must be greater to cause a change in the manufacturer's choice. In other words, an increase in product quality causes the impact of the inconvenience cost and salvage value coefficient to become less prominent.

The underlying reason for this observation is that high product quality indicates a high selling price and high salvage value. For those who cannot afford to buy due to the increase in product quality, when experiencing the need to use the product, they must rent it from the sharing market. Under such circumstances, they are more tolerant of the inconvenience cost incurred by using a product that does not belong to them. For those who originally planned to rent, the high salvage value brought about by the high quality urges them to change their mind and purchase. Therefore, the salvage value coefficient must decrease greatly to dissuade these people from buying and resort to renting. Hence, the manufacturer should first determine the quality range to which its products belong and then combine the inconvenience cost and the salvage value coefficient to take the decision of whether or not to participate in the shared market.

Figure 4 first reveals that, for any given pooling effect coefficient $(\gamma)$, the decrease in the operational cost of product sharing $(f)$ motivates the manufacturer to provide product sharing to complement its sales. When the operational cost is not very high, as the pooling effect coefficient decreases (or the pooling effect improves), the manufacturer's optimal decision evolves from not providing to providing sharing services. When the operational cost is very high, it is better for the manufacturer to adhere to traditional sales and not join the sharing market. The reason for this observation is similar to the first result in Figure 3. Because joining the sharing market will squeeze the profit of the sales market, and the reduction in the operational cost will lead to an improvement in the sharing revenue by increasing the aggregate usage and sharing price. Therefore, low operational costs enable the manufacturer to harvest more from the sharing market to balance the loss from the sales market. Managerially, to reduce the operational cost, manufacturers should improve the interconnection level of product sharing. Considering car sharing as an example, not only must the shared car itself have a high degree of cloud services to ensure real-time online operation, but more importantly, the manufacturer should also use the big data platform to obtain "portraits" of users and analyze the city's operation and traffic conditions, etc., to optimize sharing services. In addition, designing more fuel-efficient products, such as green electric cars, is in line with reducing the operational cost.

Second, comparing Figures 4(a) and 4(b), the result is consistent with what we obtained from Figures 3(a) and 3(b). High product quality renders the sharing market more attractive to the manufacturer. The improvement in the product quality $(q)$ weakens the influence of the operational cost but strengthens the impact of the pooling effect on the manufacturer's provision decision. When $q$ is low, for any given value of the pooling effect coefficient, a slight decrease 


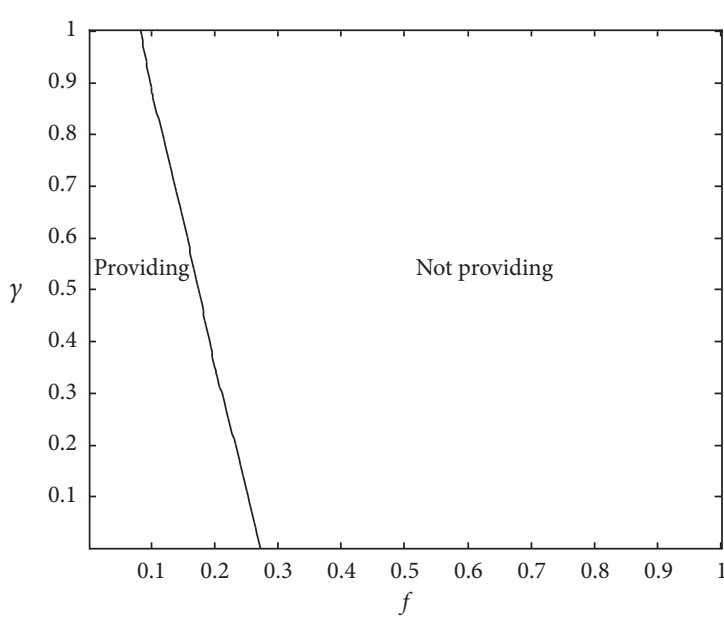

(a)

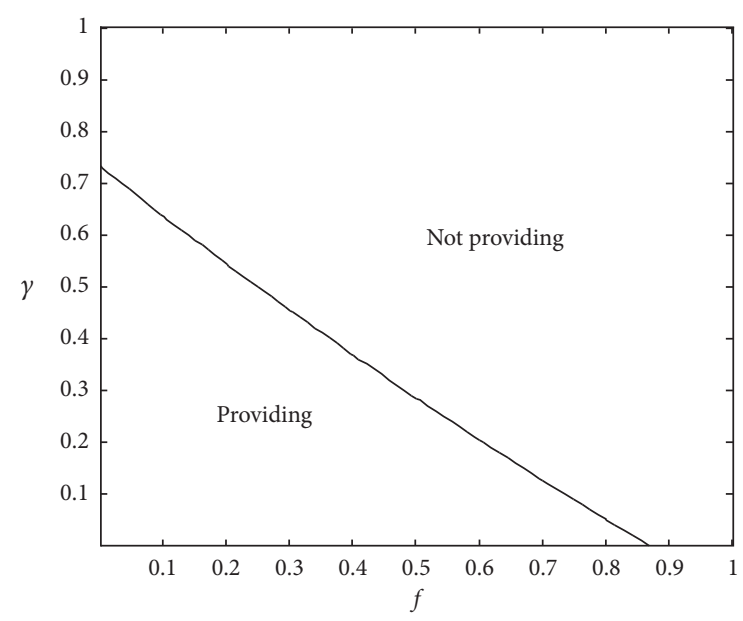

(b)

Figure 4: The effect of $f$ and $\gamma$ on manufacturer's decision. (a) $q=0.35$. (b) $q=0.95$.

in the operational cost will cause a change in the manufacturer's provision decision. When the operational cost is not very high, similarly, a slight decrease in the pooling effect coefficient will also cause this change. However, when the product quality is high, the degree of such a decrease must be larger to result in a change in the manufacturer's provision decision.

To summarize, the improvement of product quality renders the impact of the operational cost less significant and the impact of the pooling effect more important because an increase in the product quality has a twofold effect. On the one hand, high product quality leads to a high selling price, causing more people to tend to rent the product. The increase in the sharing demand enables the manufacturer to bear the high operational cost. On the other hand, high product quality indicates a high production cost. When the strength of the pooling effect is certain, the total production cost of shared products rises. A manufacturer can only join the sharing market when the pooling effect is strong; if it has already joined, it can increase the advantages of joining the shared market by reducing the number of launches-in other words, by improving the pooling effect. An important implication of the above observation is that, if the manufacturer is powerless to reduce its operational cost, it can influence the renters' sharing demand generation through pricing strategies, such as through the surge pricing mechanism that is widely used in Didi and Uber. On special weather days and during peak periods, the price of using a car will be multiplied by a factor and thus increase.

4.3. Consumer Surplus and Social Welfare. In this part, we draw a comparison between models with and without product sharing and address the social implications. In particular, we compare the value of the consumer surplus and social welfare before and after the manufacturer joins the sharing market. Recall that, in Section 3, when the manufacturer only acts as the seller, a consumer who is indifferent between buying and leaving the market is denoted as $\mu^{S}$. When the manufacturer acts as both the seller and the sharing service provider, a consumer who is indifferent between buying and renting is denoted as $\mu^{R}$. Thus, we obtain the consumer surplus with and without product sharing.

$$
\begin{aligned}
\mathrm{CS}^{S *} & =\int_{\mu^{S}}^{1} U_{s}^{S} \mathrm{~d} \mu=\frac{q^{2}\left(k_{2} q-k_{1} q+2\right)^{2}}{32}, \\
\mathrm{CS}^{R *} & =\int_{0}^{\mu^{R}} U_{s}^{R} \mathrm{~d} \mu+\int_{\mu^{R}}^{1} U_{r}^{R} \mathrm{~d} \mu \\
& =\frac{q^{2}\left[2(d+f)-q^{2}\left(k_{1}-k_{2}-k_{1} \gamma+k_{3} \gamma\right)\right]^{2}}{8(d+f+q)^{2}} .
\end{aligned}
$$

First, intuitively, from Figure 5, providing the product sharing services hurts consumers more than not providing them when product quality is high. In particular, we find that the improvement in quality leads to a rapid increase in the consumer surplus before the manufacturer provides product sharing, while the consumer surplus after the manufacturer provides product sharing first slowly increases and then slowly decreases.

High quality causes buyers to give high valuation for buying the products. Although the selling price increases with the product quality, the salvage value of the purchased product also increases, which can reduce the utility loss brought about by a high purchase cost. Therefore, increasing the product quality rapidly increases the consumer surplus before the manufacturer provides product sharing services. After the manufacturer provides sharing services, the improvement in product quality does not increase either the valuation of using the shared product or the sharing price. Therefore, the change in the consumer surplus after the manufacturer joins the sharing market is slow with the increase in product quality. When the product quality is greater than the medium range, an improvement in the product quality will lead to a slow decrease in the consumer 


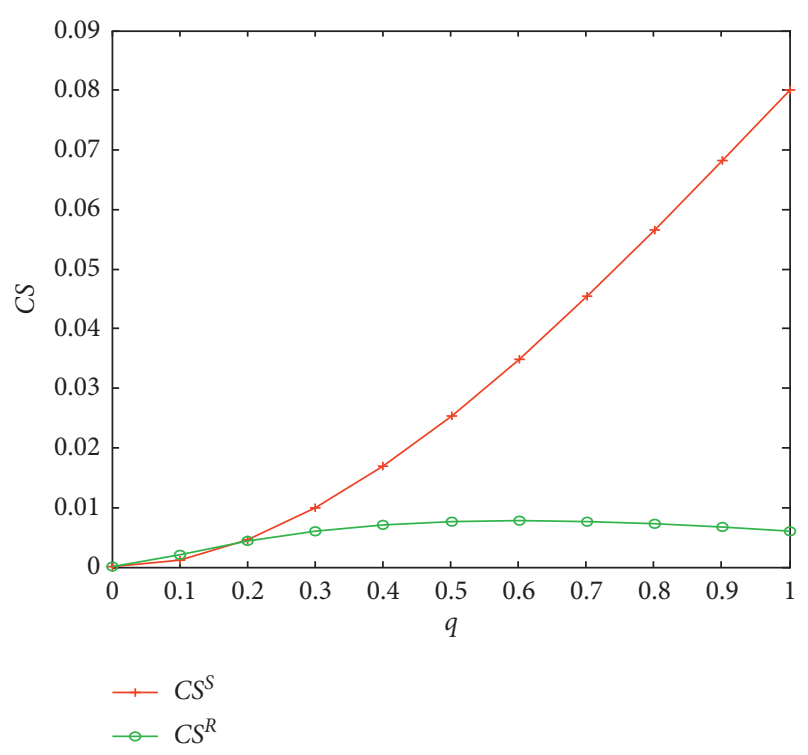

FIgURE 5: The effect of $q$ on consumer surplus.

surplus because, if the quality of a product is particularly high, such as for luxury goods, then consumers might only need to use them on special occasions, so the frequency of their use will be low. Therefore, the consumer surplus under such conditions will decrease with increasing product quality.

Second, launching low-quality products for sharing can benefit consumers. When the product quality is low, including product sharing services brings a higher level of consumer surplus than not including product sharing services. Otherwise, the consumer surplus of including product sharing services is lower than the alternative. Recalling Section 4.1, when the product quality is low, joining the sharing market leads to a lower selling price and sharing price. Therefore, the consumer surplus under this circumstance is larger than that when not providing product sharing services. When product quality is high, the manufacturer's joining of the sharing market greatly increases the selling price and the sharing price. Although the salvage value for owners increases, the consumer surplus remains smaller under this condition than not providing product sharing services.

Next, we examine the effect of product sharing on social welfare. Social welfare is the sum of the consumer surplus and the manufacturer's profit. The social welfare with and without product sharing is as follows:

$$
\begin{aligned}
\mathrm{SW}^{S *}= & \frac{q(q+2)\left(k_{2} q-k_{1} q+2\right)^{2}}{32}, \\
\mathrm{SW}^{R *}= & \frac{q^{2}\left[q\left(k_{1}-k_{2}-k_{1} \gamma+k_{3} \gamma\right)+2\right]^{2}}{8(d+f+q)}-\frac{q^{2}\left(k_{1}-k_{2}\right)}{2} \\
& +\frac{q^{2}\left[2(d+f)-q^{2}\left(k_{1}-k_{2}-k_{1} \gamma+k_{3} \gamma\right)\right]^{2}}{8(d+f+q)^{2}} .
\end{aligned}
$$

Next, we investigate how product quality affects social welfare in Figure 6.

From Figure 6, first, as product quality increases, social welfare increases regardless of whether or not the manufacturer provides product sharing because, generally, the improvement of product quality increases the consumer surplus and profits regardless of whether or not the manufacturer joins the sharing market. Second, the social welfare after the manufacturer joins the sharing market is generally greater than that before joining. In particular, with the increase in product quality, the social welfare before the manufacturer joins the sharing market grows steadily, while that after the manufacturer joins the sharing market grows first slowly and then rapidly because, after the manufacturer provides sharing services, the great increase in the manufacturer's profit compensates for the decrease in the consumer surplus.

The above results suggest that, as the product quality rises, the manufacturer benefits more from product sharing than consumers. B2C product sharing results in the better utilization of some idle resources and excess manufacturer capacity, which can be considered a form of supply-side reform. For instance, the emergence of bike sharing has released the production capacity of old bicycle factories, such as Shanghai Phoenix and Tianjin Feige, providing a window for them to innovate technologically and find new markets. Intuitively, from the social planners' perspective, if they want to leverage $\mathrm{B} 2 \mathrm{C}$ product sharing to promote more adequate use of idle resources and excess capacity, and if they regard the sharing economy as a new economic growth point, they should not only formulate policies to encourage enterprises to support traditional manufacturers in providing sharing services but, more importantly, also consider the interests of consumers. For example, when traffic accidents occur while using shared cars, consumers' right to claim is often not guaranteed. The disclosure of personal information while scanning a QR code to use a shared bicycle also causes trouble for consumers. The current "Consumer Rights Protection Law" is lacking in sharing economy supervision. The inadequate updating of laws and regulations has directly caused the relevant departments to be unable to rely on supervision, and the legitimate rights and interests of consumers cannot be protected. This situation has become another major hurdle restricting the development of the sharing economy. Therefore, to promote a sound and healthy development of the sharing economy, the interests of enterprises and consumers must be considered at the same time.

Relevant departments should work with relevant scientific research institutions to conduct detailed investigations into the new issues that have emerged in the current sharing economy and analyze outstanding issues, such as the difficulty in defining supervisory entities, unclear penalty and compensation systems, cumbersome consumer rights protection procedures, and the difficulty of supervising overlord clauses. In addition, discussions and summaries of relevant management measures should be incorporated into the relevant laws and regulations in a timely manner, or supplementary formulations of relevant regulations should 


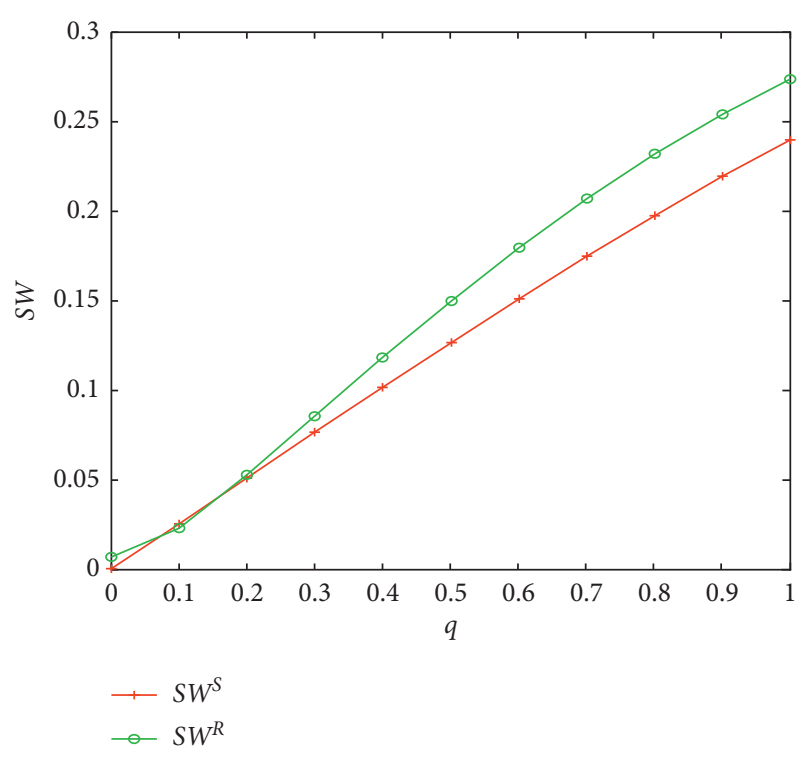

Figure 6: The effect of $q$ on social welfare.

be created. For example, in light of the problem that online transactions do not generate invoices and consumers' subsequent quality assurance services are difficult to guarantee, relevant laws could be explored to establish a format for "online transaction contracts" to force businesses to charge consumers or bear the costs of items and services. This format should define delivery and payment terms, purchase restrictions and limiting conditions (guardian's permission, geographical and time restrictions, purchase limits, etc.), effective after-sales service information, guarantees and guarantee terms, etc. For another example, in response to the problem that consumers often encounter operator bankruptcy and difficult-to-refund deposits, the relevant laws and regulations could clearly use shared physical objects as deposits, and based on express provisions in the laws and regulations, the relevant departments' illegal investigation and punishment work would be even greater to further safeguard the fairness and justice of the sharing economy market and effectively protect the rights and interests of consumers.

\section{Discussion and Implications}

In this section, we discuss the key findings in our research and analyze their implications from the academic and industry perspectives.

Different from other research in this area, our study reveals that the renter's inconvenience cost and the operational cost of sharing businesses are two key forces that steer the manufacturer's choice on whether or not to include product sharing services to complement its sales business. To be specific, a manufacturer that includes product sharing with its traditional sales business is motivated by the low inconvenience cost of renters and low operational cost of its sharing business. The intuition behind this result is the trade-off between the increase in sharing demand and the increase in operational cost due to convenient sharing experience. Therefore, manufacturers that contemplate joining the sharing market could take steps to balance between the sharing convenience improvement and the operational cost increase. Considering car sharing, for example, from the perspective of reducing the inconvenience, the key point lies in increasing the convenience of car pick-up and return, and optimizing the user experience. Currently, the major sharing car brands are constantly optimizing the network layout in car hygiene, driving comfort, and other issues of concern for users. From the perspective of reducing operational cost, it is critical to reduce labor cost and improve scheduling efficiency. Considering shared electric vehicles as an example, it is necessary to achieve the integration of vehicle, pile, and location. The manufacturer can encourage car renters to plug in the charging socket after use to reduce personnel investment. In addition, improving the intelligent system of scheduling can also contribute to reducing the operational cost.

In addition, the product quality functions as a moderator to alleviate the effect of the renter's inconvenience cost and operational cost on the manufacturer's business mode evolution. In particular, high product quality motivates manufacturers to provide sharing services because, although high-quality products tend to have more complex operation processes and higher operational costs, they also lead to the cannibalization effect. The sales market is eroded by the sharing market when product quality is high. This result indicates that manufacturers contemplating inclusion of product sharing to complement their sales business should consider their product quality level. For those already providing sharing services, to gain advantages, they must improve their product quality, for example, improving the navigating ability of electric vehicles for sharing and improving the intelligent level of car sharing.

Our findings also indicate that sales business plus product sharing services, which have been widely adopted by many manufacturers, do not always outperform pure sales business. This result holds when the renter's inconvenience cost or the operational costs of sharing are high. This finding implies that, depending on the renter's using experience and the operation management efficiency, a wise choice must be made between maintaining the status quo and providing product sharing services. For example, due to the inconvenient use brought about by an insufficient number of borrowers and return stations, the shared basketball firm "pig ball" failed in 2019. In addition, many toy sharing enterprises have also closed down, for example, Le Tong and wanjuzuzu because children are too careless when using toys, causing high operation and maintenance costs. Thus, when manufacturers contemplate whether or not to join the sharing market, they must evaluate their operation management ability and conduct full research on consumers' use processes.

\section{Conclusion and Future Research Direction}

In this paper, we model the problem of a manufacturer that has only sold products previously and is now deciding whether or not to provide product sharing services. Our 
study provides managerial insights into the manufacturer's decision in such cases. We also analyze the impact of product sharing on the traditional sales market. Then, we compare the models with and without product sharing to address the social implications of the decision. Several results are obtained. First, a low level of renter's inconvenience cost and operational cost motivates the manufacturer to join the sharing market to complement its product sales. Otherwise, the manufacturer prefers to adhere to its traditional sales business. The increase in product quality encourages the manufacturer to provide product sharing services. Second, product sharing exerts a cannibalization effect on sales. The demand in the sales market shrinks while the selling price increases when the renter's inconvenience cost is low, and the product quality is high. Third, simultaneously providing product selling and sharing businesses is a win-win situation for both consumers and the manufacturer.

We indicate several directions for future research. First, manufacturers' strategic decisions on business models are a complex problem involving both internal and external factors. To make our research more focused, we mainly addressed the impact of internal factors. However, the external ones are as influential in certain circumstances. For example, the impact the COVID-19 outbreak had on the market environment and consumers' willingness to use shared products will affect the final decisions of manufacturers. Further research could develop a model that covers the complexity of the external business environment and internal operational management. Second, in this paper, we assume that the pooling effect has a proportional effect on the number of products that must be launched in the sharing market. However, the influence of the pooling effect is much more complex in reality. It depends on the density of potential consumers, the degree of synchronicity of the sharing market demand, the category of the product, etc. In the future, researchers could explore a more complex form of the pooling effect to better understand its influence. Third, the size of the operational cost of product sharing is actually related to the pooling effect. By leveraging a strong pooling effect, the operational cost of the sharing business will be reduced. However, to render our research questions more focused, we ignored the relationship between them. Fourth, there is a certain relationship between the degree of inconvenience and operating costs. When a firm takes action to reduce the inconvenience of sharing, it must bear a high operational cost. In the future, researchers could determine the relationship between these factors. Fifth, scholars could study the problem of the manufacturer's business mode selection in more complex scenarios. We only consider the monopoly case, in which one manufacturer decides to change its sales-only mode to gain advantage in the sharing economy. Researchers can focus on the duopoly case in the future to study the interplay between two manufacturers' business mode choices. In addition, in our study, we omit the firms that already provide sharing services on the market. Future studies could investigate the competition between such a firm and a manufacturer that provides both sales and sharing. In such cases, the effect of product sharing on the competition between the firm and the manufacturer must be considered.

\section{Appendix}

\section{A. Proof of Theorem 1}

Proof of Theorem 1. Before including product sharing services, the manufacturer only sells products to consumers. When $U_{s}^{S} \geq 0$, the consumer's utility of buying the product is positive, and he/she chooses to buy the product, i.e., $\mu \in\left[\mu^{S}, 1\right]$ and $\mu=\left(p_{s}^{S}-\varepsilon_{s} / q\right)$. Thus, the sales demand and the manufacturer's profit are as follows:

$$
\begin{aligned}
& D_{s}^{S}=1-\frac{p_{s}^{S}-\varepsilon_{s}}{q}, \\
& \Pi_{s}^{S}=\left(p_{s}^{S}-\frac{1}{2} k_{1} q^{2}\right)\left(1-\frac{p_{s}^{S}-\varepsilon_{s}}{q}\right) .
\end{aligned}
$$

Taking the first-order derivative of $\Pi_{s}^{S}$, we obtain $\left(\partial \Pi_{s}^{S} / \partial p_{s}^{S}\right)=(q / 2)\left(k_{1}+k_{2}\right)-\left(2 p_{s}^{S} / q\right)+1$. Let $\left(\partial \Pi_{s}^{S} / \partial p_{s}^{S}\right)$ $=0$; we derive $p_{s}^{S *}=\left(q\left(k_{1} q+k_{2} q+2\right) / 4\right)$. The second-order derivative of $\Pi_{s}^{S}$ yields $\left(\partial^{2} \Pi_{s}^{S} / \partial p_{s}^{S 2}\right)=-(2 / q)<0$. Therefore, $p_{s}^{S *}$ is an interior point. Substituting $p_{s}^{S *}$ into $D_{s}^{S}$ and $\Pi_{s}^{S}$, we obtain

$$
\begin{aligned}
D_{s}^{S *} & =\frac{2-q\left(k_{1}-k_{2}\right)}{4}, \\
\Pi_{s}^{S *} & =\frac{q\left(k_{2} q-k_{1} q+2\right)^{2}}{16} .
\end{aligned}
$$

\section{B. Proof of Theorem 2}

Proof of Theorem 2. When $U_{s}^{R} \geq \max \left\{U_{r}^{R}, 0\right\}$, he/she will choose to buy the product; otherwise, if $U_{r}^{R} \geq \max \left\{U_{s}^{R}, 0\right\}$, he/she will choose to rent the product. Thus, when $\mu \in\left[\mu^{R}, 1\right]$, where $\mu^{R}=\left(p_{s}^{R}-\varepsilon_{s} / p_{r}^{R}+d\right)$, the consumer chooses to purchase, and the sales market demand is $D_{s}^{R}=1-\mu^{R}$; otherwise, $\mu \in\left[0, \mu^{R}\right)$, the consumer chooses to rent, and the sharing market size is $D_{r}^{R}=\mu^{R}$.

After including product sharing services, the manufacturer not only sells cars but also provides car sharing services to consumers. The consumer chooses to buy the product when $U_{s}^{R} \geq \max \left\{U_{r}^{R}, 0\right\}$, i.e., $\mu \in\left[\mu^{R}, 1\right]$ and $\mu^{R}=\left(p_{s}^{R}-\varepsilon_{s} / p_{r}^{R}+d\right)$. Thus, the sales demand and the sales profit are

$$
\begin{aligned}
D_{s}^{R} & =1-\frac{p_{s}^{R}-\varepsilon_{s}}{p_{r}^{R}+d}, \\
\Pi_{s}^{R} & =\left(p_{s}^{R}-\frac{1}{2} k_{1} q^{2}\right)\left(1-\frac{p_{s}^{R}-\varepsilon_{s}}{p_{s}^{R}+d}\right) .
\end{aligned}
$$

The consumer chooses to rent the product when $U_{r}^{R} \geq \max \left\{U_{s}^{R}, 0\right\}$, i.e., $p_{r}^{R} \leq q-d$. Therefore, the sharing 
market size, the aggregate usage, and the sharing profit, respectively, are

$$
\begin{aligned}
& D_{r}^{R}=\frac{p_{s}^{R}-\varepsilon_{s}}{p_{r}^{R}+d}, \\
& \Omega_{r}^{R}=\frac{1}{2}\left(\frac{p_{s}^{R}-\varepsilon_{s}}{p_{r}^{R}+d}\right)^{2}, \\
& \Pi_{r}^{R}=\frac{\left(p_{r}^{R}-f\right)}{2}\left(\frac{p_{s}^{R}-\varepsilon_{s}}{p_{r}^{R}+d}\right)^{2}-\frac{q^{2} \gamma\left(k_{1}-k_{3}\right)\left(p_{s}^{R}-\varepsilon_{s}\right)}{2\left(p_{r}^{R}+d\right)} .
\end{aligned}
$$

Therefore, the total profit of the manufacturer under the hybrid mode is

$$
\begin{aligned}
\Pi_{s r}^{R}= & \left(p_{s}^{R}-\frac{1}{2} k_{1} q^{2}\right)\left(1-\frac{p_{s}^{R}-\varepsilon_{s}}{p_{r}^{R}+d}\right)+\frac{\left(p_{r}^{R}-f\right)}{2}\left(\frac{p_{s}^{R}-\varepsilon_{s}}{p_{r}^{R}+d}\right)^{2} \\
& -\frac{q^{2} \gamma\left(k_{1}-k_{3}\right)\left(p_{s}^{R}-\varepsilon_{s}\right)}{2\left(p_{r}^{R}+d\right)} .
\end{aligned}
$$

The first-order condition with respect to $p_{r}^{R}$ of $\Pi_{s r}^{R}$ yields $\left(\partial \Pi_{s r}^{R} / \partial p_{r}^{R}\right)=\left(2 p_{s}^{R}-k_{2} q^{2} / 8\left(d+p_{r}^{R}\right)^{3}\right)\left\{\left(2 p_{s}^{R}-k_{2} q^{2}\right)\left(d+3 p_{r}^{R}\right.\right.$ $\left.-2 f)+2\left(d+p_{r}^{R}\right)\left[2\left(p_{s}^{R}+(1 / 2) k_{1} q^{2}\right)+q^{2} \gamma\left(k_{1}-k_{3}\right)\right]\right\}>0$.

Thus,

$$
p_{r}^{R *}=q-d,
$$

which is its upper limit. The first-order condition with respect to $p_{s}^{R}$ of $\Pi_{s r}^{R}$ yields $\left(\partial \Pi_{s r}^{R} / \partial p_{s}^{R}\right)=1-\left(\left(2 p_{s}^{R}-k_{2} q^{2}\right)(d+\right.$ $\left.f)+\left(d+p_{r}^{R}\right)\left[2 q^{2} \gamma\left(k_{1}-k_{3}\right)+2 p_{s}^{R}-k_{1} q^{2}\right] / 2\left(d+p_{r}^{R}\right)^{2}\right)$.

Substituting (B.4) into it, we obtain

$$
p_{s}^{R *}=\frac{q^{2}\left[k_{2}(d+f)+q\left(k_{1}-k_{1} \gamma+k_{3}\right)+2\right]}{2(d+f+q)} .
$$

Substituting (B.4) and (B.5), we obtain

$$
\begin{aligned}
& D_{s}^{R *}=1-\frac{q\left[q\left(k_{1}-k_{2}-k_{1} \gamma+k_{3} \gamma\right)+2\right]}{2(d+f+q)}, \\
& D_{r}^{R *}=\frac{q\left[q\left(k_{1}-k_{2}-k_{1} \gamma+k_{3} \gamma\right)+2\right]}{2(d+f+q)}, \\
& \Omega_{r}^{R *}=\frac{q^{2}\left[q\left(k_{1}-k_{2}-k_{1} \gamma+k_{3} \gamma\right)+2\right]^{2}}{8(d+f+q)^{2}}, \\
& \Pi_{s r}^{R *}=\frac{q^{2}\left[q\left(k_{1}-k_{2}-k_{1} \gamma+k_{3} \gamma\right)+2\right]^{2}}{8(d+f+q)}-\frac{\left(k_{1}-k_{2}\right) q^{2}}{2} .
\end{aligned}
$$

\section{Data Availability}

The data are already included within the article.

\section{Conflicts of Interest}

The authors declare that they have no conflicts of interest.

\section{Acknowledgments}

This study was supported by the National Social Science Foundation of China under Grant no. 18BGL265.

\section{References}

[1] B. Jiang and L. Tian, "Collaborative consumption: strategic and economic implications of product sharing," Management Science, vol. 64, no. 3, pp. 1171-1188, 2018.

[2] R. Belk, "You are what you can access: sharing and collaborative consumption online," Journal of Business Research, vol. 67 , no. 8 , pp. 1595-1600, 2014

[3] L. Tian and B. Jiang, "Effects of consumer-to-consumer product sharing on distribution channel," Production and Operations Management, vol. 27, no. 2, pp. 350-367, 2018.

[4] B. Dai and Y. Nu, "Pricing and capacity allocation strategies: implications for manufacturers with product sharing," Naval Research Logistics (NRL), vol. 67, no. 3, pp. 201-222, 2020.

[5] Y. Yu, Y. Dong, and X. Guo, "Pricing for sales and per-use rental services with vertical differentiation," European Journal of Operational Research, vol. 270, no. 2, pp. 586-598, 2018.

[6] V. V. Agrawal and I. Bellos, "The potential of servicizing as a green business model," Management Science, vol. 63, no. 5, pp. 1545-1562, 2017.

[7] N. U. I. Hossain, F. Nur, and M. A. Habib, "Achieving competitve advantage through practicing TQM tools in pharmaceuticals company," Journal of Mechanical Engineering, vol. 43, p. 7, 2013.

[8] Q. Sun, Y. He, Y. Wang, and F. Ma, "Evolutionary game between government and ride-hailing platform: evidence from China," Discrete Dynamics in Nature and Society, vol. 2019, Article ID 9545102, 14 pages, 2019.

[9] D. Ding and B. Shuai, "A traffic restriction scheme for enhancing carpooling," Discrete Dynamics in Nature and Society, vol. 2017, Article ID 9626938, 9 pages, 2017.

[10] S. Benjaafar, G. Kong, X. Li, and C. Courcoubetis, "Peer-to-Peer product sharing: implications for ownership, usage, and social welfare in the sharing economy," Management Science, vol. 65, no. 2, pp. 477-493, 2019.

[11] T. A. Weber, "Product pricing in a peer-to-peer economy," Journal of Management Information Systems, vol. 33, no. 2, pp. 573-596, 2016.

[12] Z. Liu, J. Feng, and J. Wang, "Effects of the sharing economy on sequential innovation products," Complexity, vol. 2019, Article ID 3089641, 18 pages, 2019.

[13] V. Abhishek, J. A. Guajardo, and Z. Zhang, "Business models in the sharing economy manufacturing durable goods in the presence of peer-to-peer rental markets," SSRN Electronic Journal, vol. 131, 2019.

[14] Y. Li, X. Bai, and K. Xue, "Business modes in the sharing economy: how does the OEM cooperate with third-party sharing platforms," International Journal of Production Economics, vol. 11, 2019.

[15] P. Yan, J. Pei, and A. Chinchuluun, "Strategic decisions of sales and pay-per-use rentals under incomplete product availability," Journal of Global Optimization, vol. 78, no. 4, pp. 671-691, 2020.

[16] H. Ke, S. Chai, and R. Cheng, "Selling or sharing: business model selection problem for an automobile manufacturer 
with uncertain information," Journal of Intelligent \& Fuzzy Systems, vol. 36, no. 1, pp. 609-624, 2019.

[17] M. Razeghian and T. A. Weber, "The advent of the sharing culture and its effect on product pricing," Electronic Commerce Research and Applications, vol. 33, 2019.

[18] P. Blaettchen, S. Hasija, and N. Taneri, "Sharing of heavy equipment," Working Paper, 2020.

[19] I. Bellos, M. Ferguson, and L. B. Toktay, "The car sharing economy: interaction of business model choice and product line design," Manufacturing \& Service Operations Management, vol. 19, no. 2, pp. 185-201, 2017.

[20] B. Jiang, L. Tian, and Y. Xu, "Manufacturer's entry in the product-sharing market," Working Paper, 2018.

[21] J. Pei, P. Yan, S. Kumar, and X. Liu, "How to react to internal and external sharing in $\mathrm{B} 2 \mathrm{C}$ and $\mathrm{C} 2 \mathrm{C}$," in Production and Operations Management Wiley-Blackwell, Hoboken, NJ, USA, 2020.

[22] S. Balasubramanian, S. Bhattacharya, and V. V. Krishnan, "Pricing information goods: a strategic analysis of the selling and pay-per-use mechanisms," Marketing Science, vol. 34, no. 2, pp. 218-234, 2015.

[23] G. P. Cachon and P. Feldman, "Pricing services subject to congestion: charge per-use fees or sell subscriptions?" Manufacturing \& Service Operations Management, vol. 13, no. 2, pp. 244-260, 2011.

[24] K. Sato and K. Nakashima, "Optimal pricing problem for a pay-per-use system based on the Internet of Things with intertemporal demand," International Journal of Production Economics, vol. 221, 2020.

[25] S. Li, Q. Luo, L. Qiu, and S. Bandyopadhyay, "Optimal pricing model of digital music: subscription, ownership or mixed?" Production and Operations Management, vol. 29, no. 3, pp. 688-704, 2019.

[26] M. W. Toffel, "Contracting for servicizing," Working Paper, 2008.

[27] K. T. Ladas, S. Kavadias, and C. Loch, "Product selling versus pay-per-use services: a strategic analysis of competing business models," Working paper, 2019.

[28] S. M. Gilbert, R. S. Randhawa, and H. Sun, "Optimal per-use rentals and sales of durable products and their distinct roles in price discrimination," Production and Operations Management, vol. 23, p. 12, 2014.

[29] V. V. Agrawal, M. Ferguson, L. B. Toktay, and V. M. Thomas, "Is leasing greener than selling?" Management Science, vol. 58, no. 3, pp. 523-533, 2012. 